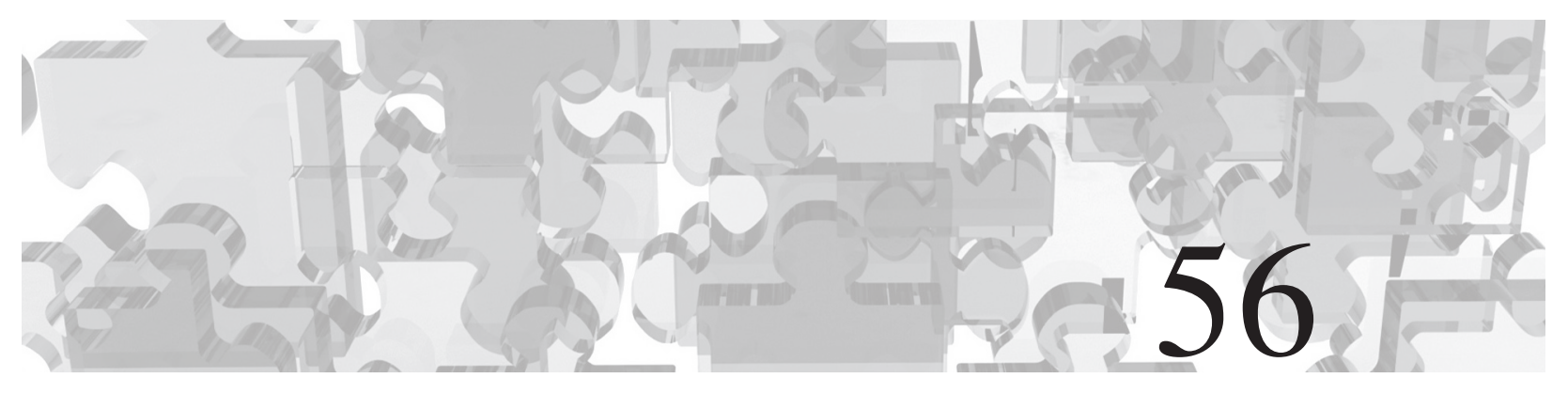

\title{
Functions of Student-centred Approaches to Assessment in Teacher Education
}

\author{
Surette van Staden and Brigitte Smit
}

\section{INTRODUCTION}

This chapter attends to learning-centred (also referred to as student-centred) approaches to assessment in teacher education. The term student-centred is used in this chapter, since learners in the South African context refers to school-going children, while students denote those individuals who are registered and studying at tertiary institutions. The student-centred approach is nested in constructivist thinking, assuming a dynamic relationship between the teacher-educator and the student-teacher, where the teacher-educator assumes the role of coach and mentor and the student-teacher is an active participant in the assessment process. This relationship implies that assessment is not solely the domain of some removed intellectual authority. Instead, the student-teacher plays an active role in learning and assessment, through a process of collaboration and dialogue. A constructivist approach suggests active participation in and interaction with assessment tasks, which are facilitated by the teacher-educator. For example, dialogue between the teacher-educator and the student-teacher can be fostered through the negotiation of assessment task criteria. Such dialogue can lead to authentic, functional and individualised assessment in a learning context that is meaningful for the student-teacher. The inseparably linked elements of student learning and assessment, assessment for learning during learning task execution, and the principles of good assessment are the core beliefs underpinning the learning-centred approach to teaching assessment.

This chapter begins by presenting a case study of the Postgraduate Certificate in Education (PGCE) programme, which we offered in a leading university in 
South Africa. In foregrounding the chapter with an illustrative case study we discuss how constructivism, as a theoretical perspective of a person-centred approach to assessment can be instructed in higher education. The chapter also provides a review of literature on how person-centred assessment in teacher education can be taught. Lastly, the chapter concludes with the implications for teacher education practices in terms of what and how in-service teachers can learn. It also speaks to how effective practices within particular domains in teacher education can be transformed in light of possible future directions in teacher education assessment research from a person-centred perspective.

\section{A CASE STUDY OF STUDENT TEACHER ASSESSMENT PRACTICE IN SOUTH AFRICA: POSTGRADUATE CERTIFICATE IN EDUCATION PROGRAMME}

In this section, a case study from a South African university setting is used to illustrate three aspects of the classroom dynamics in teaching assessment. First, a picture is painted of the diversity of the student population in terms of background, academic proficiency and experience to provide the reader with a context against which person-centred assessment takes place in this instance. Second, the relationship between the teacher-educator and the student-teacher is elaborated to provide evidence that assessment is not imparted to students from a place of authority, but that the student-teacher plays an active role in learning and assessment, through a process of collaboration and dialogue. Third, the case study explores attempts to develop a deep learning approach among students, where two different but interrelated approaches are explored, namely studentcentred learning and assessment and the accompanying role of feedback and formative assessment from a person-centred approach, which ensures that assessment forms part of the learning process.

The Postgraduate Certificate in Education (PGCE) is presented as part of the professional teacher training qualifications presented by the Faculty of Education at the University of Pretoria in South Africa. It is a professional qualification that has grown in popularity among students who wish to obtain a teaching qualification after having obtained their first degrees. These first degrees vary between anything from a general Bachelor's degree, to a degree in Commerce, Natural Science, Performing Arts, or Theology. At a specific university in South Africa, the programme has seen a rise in numbers over the last few years, starting with 96 students registered in 2013 to an increase of 130 registered students in 2014 and, most recently, 180 registered students in 2015. Future plans for an even greater influx of students could see the programme accommodating as many as 400 students.

The programme is still dominated by female students, who comprise more than 80 per cent of students who register to specialise in teaching in the Senior 
Phase (Grades 7-9). Student ages vary greatly - from as young as 23 to 40 and older. Reasons students cite for wanting this professional certificate in teaching include:

- unhappiness with their original choice of study in which they obtained a first degree;

- desire for a change of career;

- initially being discouraged by friends and family to follow a career in teaching and now wanting to pursue their initial choice;

- being encouraged by friends and family (often themselves being in the teaching profession) to study teaching and now pursuing teaching after completing a first degree;

- (for older students) their children leaving home, creating the opportunity to pursue meaningful studies that would allow them to follow their passion;

- not being able to obtain gainful employment with only their first degrees; and

- being refused entry into fields of study that require strict selection criteria (e.g. Psychology).

Alongside the various reasons cited for entering into the PGCE programme are also varied levels of achievement therein. While some students excel in the theoretical training of their modules, others fail persistently across multiple modules. Reasons for inadequate academic achievement may include:

- inadequate English language proficiency;

- inability to attend class regularly due to family responsibilities;

- having to travel long distances and make use of unreliable public transportation;

- being diagnosed with emotional problems (such as major depression and bipolar disorder) that have not been disclosed before entry into the programme and that make keeping up with the programme content and activities more difficult; and

- financial difficulty, specifically for those students with bursaries that only make provision for tuition fees.

In light of these challenges, the programme specifically aims to develop and assist the students not only professionally but also personally. A specific anomaly observed in this programme is that many students fail to make the grade in the theoretical part of their training, yet flourish and excel once they engage in teaching practice in schools. This begs various questions regarding the ability of students to handle academic pressure and adhere to assignment deadlines and examinations, but also regarding the potential role that formative assessment can still play in assisting students to use assessment not only of learning, but assessment for learning and assessment as learning - phrases coined by Bennett (2011).

The following example of a person-centred task is provided to illustrate how students are furnished with scaffolded support for the completion of tasks in as an authentic a manner as possible of how their own assessment practice can be informed. As part of one of the core modules presented to students in assessment in the PGCE programme, students are requested to bring any test, examination or assessment exercise that they may have used to assess their students in the area of specialisation to the contact session. Students are then placed in pairs to critically discuss the rationale for the assessments' use, how the instruments align with the 
goals they want to achieve with their students, reasons for item selection, and possible strengths or weaknesses with regard to issues of practicality, authenticity, fairness, objectivity, validity and reliability. Students are encouraged to provide critical, yet constructive feedback to each other in thinking through their respective assessment tasks. The aim of this exercise is to stimulate sound learning practices among students, while involving students actively in engaging with criteria, quality and their own and peer attempts at using assessment effectively.

Following this exercise of critically thinking through an existing assessment task, students are then guided in the assembly of a test, examination or assessment task (regardless of its formative or summative nature), and the use of an assessment framework as a blueprint for planning the test, examination or assessment exercise.

Based on the theoretical principles of good assessment, students are then shown how possible revisions, eliminations or improvements of items can be made in an effort to ensure that the assessment task is as closely aligned to the learning outcomes as possible to gauge student achievement, whether for summative or formative purposes, as accurately as possible. The exercise concludes by providing students with an opportunity to plan and construct their own test, examination or assessment exercise in their area of specialisation, using the assessment framework as a blueprint to guide their thinking. In this way, students are taken through a process, starting by discussing their own work critically in light of their theoretical knowledge, then exposing them to the idea and function of an assessment framework, and then allowing them to apply their new-found skills in the improvement of a test, examination or assessment. In providing feedback on this exercise, students not only become aware of problems in their thinking and planning around assessment, but the facilitator uses tangible evidence of student work to provide further assistance, guiding students to understand the outcomes they should reach to enhance their own teaching practice at school.

While the matter of student-centred learning is well researched, the notion of a person-centred approach to assessment is less prominent in the literature. Given the empirical evidence from our case study, where this approach was actively used, we claim that person-centred assessment enhances knowledge retention, depth of understanding and that a deep appreciation of the content is valuable for student teachers. Considering that skills such as lifelong learning and independent problem-solving are facilitated, appropriate assessments were designed in our case study to make independent meaning-making visible.

Student feedback on this exercise indicates that it allowed students for the first time to think critically about planning and designing their own assessment tasks. In this way, the responsibility of using assessment in a fair, valid and reliable way comes to the forefront, where student teachers are confronted with thoughts about using assessment as a tool for learning in their own teaching practice. One student in particular related her own story of a disgruntled parent who doubted the students' use of an assessment task. Having applied her mind critically to the task, 
applying principles of the assessment framework to guide her thinking allowed the student ample evidence to convince the parents that the assessment had indeed been used in alignment with the goals she set out to achieve and as a tool for further assistance of the students in her class. This signals that the teaching of assessment as part of a teacher education qualification at a tertiary institution highlights the double-edged nature of assessment: while teaching student teachers about assessment, we are also educating teachers to learn to think about their own assessment of students when they begin teaching. The following section deals with the issue of assessment in teacher education in more detail.

\section{ASSESSMENT IN TEACHER EDUCATION}

\section{A Student-Centred Approach to Assessment}

Worldwide, the face of higher education is changing. These changes are observed in the increased numbers of students and (in some countries) what Barrington (2004) refers to as the 'massification' of higher education. Yorke (2003) refers to differentially salient features of higher education across the world - namely, an increasing concern with attainment standards, leading to greater emphasis on summative assessments of outcomes, increasing student/staff ratios, with implications for individual attention that students can expect to receive, and changes in curricular structures in favour of greater unitisation, more frequent assessments of outcomes and less opportunities for formative feedback - that place the sector under pressure. The demands, in addition to teaching, placed on staff result in added pressure to be seen as 'research active', able to generate funds, perform public service, and engage in intra-institutional administration (Yorke, 2003). Increases, not only in the numbers but also in the diversity of the student population, are challenging the way in which things are done within the sector. Lea, Stephenson and Troy (2003) argue that increases in the number of mature students, international students, and students with disabilities have changed the needs of students. Meanwhile, teaching and learning in higher education remain inseparably linked. As Healey (2000) stresses, the scholarship of teaching is as much about learning as it is about teaching.

Accordingly, Rust (2002) claims that there has been a paradigm shift, specifically in English-speaking countries, over the last decade, from a focus on teaching to a focus on learning in higher education. In the United Kingdom for instance, far greater emphasis is now placed on the development of skills specifically, more general, transferable 'life' skills. Accompanying this shift has been an increased emphasis on the development of study guides and materials in terms of intended student-learning outcomes (Rust, 2002). Despite these paradigmatic shifts, there still seems to be a significant lag in the connection between changes in teaching methods and changes in how assessment is conducted. 
For most courses, study materials are written in terms of the coursework accompanied by four or five learning outcomes, yet the assessment tasks associated with these outcomes are questionable at best. In this regard, Rust (2002) cites examples of students being encouraged to read more widely on the topic of discussion; yet, if the examination can be answered sufficiently by question spotting, the extent of learning that has actually occurred remains limited. Similarly, the mere inclusion of the word 'evaluate' in any question does not necessarily mean that students' evaluation skills are, in fact, being assessed. In many cases, the answer can purely be provided from memory or from notes that have been written during lectures or contact sessions.

The examples cited by Rust (2002) may point to the distinction that needs to be made between deep and surface approaches to learning, specifically in light of the changing landscape of higher education. Characteristics of the surface approach are a reliance on a heavy workload, with an excessive amount of course work or material; a high number of class contact hours; and little opportunity for in-depth engagement with subject matter, linked to limited subject choices or methods of study, ultimately culminating in a threatening or anxiety-provoking assessment experience (Rust, 2002). Opposed to the surface approach is the deep approach to learning, whereby students are encouraged to want and need to know, borne out of an intrinsic motivation and a curiosity generated through interaction with others from a well-structured knowledge base. This means that subject content is taught within integrated wholes and knowledge is required to be related to other knowledge (Rust, 2002). When students take the deep approach to their work, they are more likely to be intrinsically motivated, with an understanding of the relevance and importance not only of what they are learning but also of how they will be assessed. If students regard an assessment task purely as an obstacle to get through in order to pass, they are likely to take a surface approach to learning.

In order to develop a deep learning approach among students, two different, but interrelated approaches are explored, student-centred learning and assessment and the accompanying role of feedback and formative assessment from a person-centred approach, which ensures that assessment forms part of the learning process.

Student-centred learning implies active engagement in learning and learner responsibility for the management of learning (Nicol \& Mafarlane-Dick, 2006). Learning is not regarded as a simple acquisition process based on teacher transmission. Instead student-centred perspective is conceptualised as a process where students actively construct their own knowledge by interacting with subject content, transforming and discussing it with others so as to make internalised meaning and connections with what is already known (Nicol \& Macfarlane-Dick, 2006). Lea, Stephenson and Troy (2003) in this context describe student-centred learning as a reliance on active rather than passive learning, an emphasis on deep learning and understanding, increased responsibility and accountability on the part of the student, an increased sense of autonomy on the part of the student, and 
an interdependence between the teacher and the student, based on mutual respect whereby students are consulted about the teaching and learning process. Kanjee and Mthembu (2015) add their voices to this argument by stating that once teachers change their understanding and beliefs about assessment, their teaching practice will also change. Stiggins (2009), as cited by Kanjee et al. (2015) proposed seven assessment competencies, namely the ability to connect assessment to clear purpose, clarifying achievement expectations, applying proper assessment methods, developing quality assessment exercises and scoring criteria, avoiding assessment bias, communicating effectively about student achievement, and using assessment as an instructional intervention. The last two points in particular, speak to a concept of 'learning oriented assessment' (or LOA), as referred to by Carless (2015), which aims to promote assessment as a way of developing productive student learning processes, regardless of its formative or summative nature. LOA is encapsulated by three principles that state that assessment should be designed to stimulate sound learning practices among students, it should involve students actively in engaging with criteria, quality and their own and peer performance, and feedback should be timely to support current and future learning (Carless, 2015). These principles make it clear that a person-centred approach to teaching and assessment shifts the emphasis from the teacher to the student, the diversity of student needs must be appreciated and accommodated (Lea et al., 2003). Furthermore, student-centred teaching, aims and focuses more on the students and their learning, instead of the teacher and teaching (Postareff, Lindblom-Ylänne \& Nevgi, 2007). Student-centred learning and assessment encourages students to construct their own knowledge in striving to become independent learners. Baeten, Kyndt, Stryuven and Dochy (2010) recognise various definitions and forms of student-centred learning, but all seem to agree that such learning aims to foster deep learning and understanding. Based on the case study we claim that student-centred learning and accompanying assessment has the potential to enhance educational outcomes for students in higher education. Lea et al. (2003) support this claim that student-centred learning has the potential to enhance learning motivation, retention and knowledge, depth of understanding, and an appreciation for the content that is taught.

Assessment of student learning is an important task in the teaching and learning process (Ma \& Zhou, 2000). In general, assessment is regarded as the process of gathering information to monitor progress and make educational decisions. Similarly, Boston (2002) refers to assessment as all diagnostic activities that students and teachers undertake to alter teaching and learning. Assessment may refer to tests but may also include other forms of information gathering, such as observations and interviews, and therefore relies on multiple and diverse sources to develop a deep understanding of what students know, understand, and can do. According to Gareis and Grant (2015), the essence of assessment is the evaluation of learning achievement or the progress of learners towards the achievement of learning intentions, on the one hand, and the assessment of the learning 
process and how learners are assisted to reach said learning intentions, on the other. According to Black (1998), the aim of assessment should always be to improve learning.

Given the empirical evidence from our case study, where the person-centred approach was actively used, we claim that person-centred assessment enhances knowledge retention, depth of understanding and a deep appreciation of the content that is valuable for student teachers. Considering that skills such as lifelong learning and independent problem-solving are facilitated, appropriate assessments were designed in our case study to make independent meaning-making visible. Yet while the idea of a person-centred approach holds promise as introduced to students in this case study example, its limitations should be kept in mind. In South Africa's developing context where the emphasis is still on summative assessment (as described by Kanjee and Mthembu, 2015), teacher educators might first want to establish a true understanding for the uses he uses of formative assessment or assessment for learning before a person-centred approach is realistic. Unexplored questions for our context is the extent to which a person-centred approach can work in teacher education where high stakes examinations are still the main method of qualification attainment. Faced with large class sizes, variability in student ability, background and socio-economic challenges, the personcentred approach may only prove to be one element of many that is still needed to scratch the surface of an adequate understanding of the true nature of formative assessment.

\section{The Role of Feedback and Formative Assessment in Teacher Education}

The role of assessment in higher education extends the general definition of assessment even further, as noted by Boud and Falchikov (2007). Traditionally, assessment in higher education played a twofold role: one of certification, the other of facilitating learning. These two roles pose a daunting challenge, in that institutions of higher education today do not merely have to provide qualifications anymore. Instead, with these institutions as catalysts of lifelong learning, higher education places a focus on learning outcomes, the use of graduate attributes, and the promotion of key skills in service of an agenda of employability (Boud \& Falchikov, 2007). The process of assessment culminates in the effective use of results to improve subsequent learning. Despite this aim, assessment still has a role to fulfil, specifically in the effective use of formative assessment (also referred to as continuous assessment or assessment for learning). Authors like Bennett (2011) acknowledge the distinction between formative and summative assessment, as originally proposed by Scriven (1967), but take the debate further by referring to 'the definitional issue' and the split that has occurred in the way in which formative assessment is viewed. On the one hand, formative assessment is viewed by test publishers as a sort of diagnostic test with scores that could 
claim to have some diagnostic value better suited to instructional times and marking periods than to daily lessons. On the other hand, education researchers view formative assessment as a process, characterised not so much by its ability to produce a diagnostic score, but by how its results can be used to adapt teaching to meet students' needs. It is in this latter case where the use of formative assessment often falls short in myriad functions that assessment is supposed to play in providing feedback to students, offering diagnostic information for the teacher, providing information for record keeping, providing evidence for reports and directing curriculum and instructional changes (Earl, 2013).

Against this background, assessment in higher education (and, in this case, teacher education specifically) poses similar challenges in the way in which traditional functions of summative and formative assessment have been regarded and practiced as can be seen from the following examples.

The role of summative assessment in higher education has traditionally been to certify a level of knowledge attainment at a point of completion of a course of programme. Formative assessment in higher education poses a different set of challenges, in that it should aim to focus assessment on learning, it should separate grading and feedback, and it should be optimised through the use of peer- and self-assessment. Indeed, by definition, formative assessment, as contributor to student learning through the provision of information about performance (Yorke, 2003), is more complex than it may initially appear or in comparison with summative assessment. In support of this description of the complexity thereof, Boud and Falchikov (2007) state that formative assessment is still in need of improvement, and evidence of deficient, perfunctory feedback lacking in constructive comment is still rife in higher education contexts where, when provided, feedback is often too late to enable students to benefit from it.

More than a decade ago, Harlen and James (1997) already stated that, more often than not, formative and summative assessment are conflated, meaning that there is little evidence that genuine formative assessment is taking place. In many cases, teachers turn their assessment practices into a series of 'mini' assessments, each of which is nothing more than summative in nature. Even in higher education, these practices are exercised, with the consequence that, while policy documents and theory make space for the distinction between the two modes, the differences between them remain blurred.

In light of the problems involved in the effective use of assessment as a tool for learning with understanding, the role of formative assessment in providing improved student success could be revisited in the teaching and learning process, specifically in higher education. In 1998, influential work by Black and Wiliam (1998), in an extensive review of 250 journal articles and book chapters, found that formative assessment has the potential to raise standards and assist low-achieving students and students with disabilities. While Black and Wiliam's work focused on children of school-going age, could the same potential of formative assessment not also exist for students in higher education environments? Can 
the question still be asked regarding how assessment could be used to encourage students to want to learn and feel able to learn (Stiggins \& Chappuis, 2005)?

In attempts to understand formative assessment and the role that it can play, Harlen and James (1997) write from the assumption that an important aim of education is to learn with understanding. These authors explain that learning with understanding involves interaction with people, ideas and events in the real world. In this way, the link between formative assessment and the person centred approach become concrete and what Brookhart (2001) refers to as 'the formative process' (p. 154). Students must have a concept of their learning goal and the ability to compare their current performance against what is expected. Teachers, on the other hand, are responsible for providing timely feedback in order for students to close the gap between what is current and what is expected, and this feedback itself is often called 'formative'.

According to Gipps (1999), such a situation would ensure a teacher-student relationship based on power with the student instead of power over the student. The nature of formative assessment lends itself to this view of assessment from a sociocultural perspective, as it is not only a criterion-referenced activity, but also student-referenced (or ipsative). This means that the judgement of a student's work is not only based on the summative score obtained for the work as a whole, but also in terms of the effort that has gone into the task, the particular context of the student's work, and the progress that the student has made over time. In judgement of the work, feedback is not just given in terms of the criteria of the task, but is also dependent on the student and how the feedback could assist and encourage the student in further learning. In this regard, McMillan (2007), as cited by Ahmed and Teviotdale (2008), argue that, for formative assessment to be effective, it should improve student motivation and learning. If this aim is to be achieved, teachers must construct a cycle of continuous learning that involves their evaluation of student work and behaviour, intertwined with feedback to students and instructional correctives.

The ideas of immediacy and specificity are echoed by Stiggins and Chappuis (2005), who are of the view that formative assessment can be instrumental in reducing classroom achievement gaps on condition of four principles, namely:

1 Assessment should be driven with a clear purpose in mind.

2 Achievement expectations must be appropriate and clearly specified.

3 The assessment methods used must be regarded as teaching tools and must accurately reflect the intended targets in service of proficiency.

4 The intended users of assessment should receive results in a timely, understandable and helpful manner.

Echoing the work of Stiggins and Chappuis (2005), and reflective of how McMillan (2007) views the role of formative assessment, Nicol and MacfarlaneDick (2006) identify seven principles of good feedback practice, as synthesised from their literature review: 
- Effective feedback clearly states what good performance is in terms of goals, criteria and expected standards.

- It facilitates the development of self-assessment and reflection in learning.

- Feedback should deliver high quality information to students about their learning.

- Feedback should encourage teacher and peer dialogue around learning.

- Effective feedback should encourage positive motivational beliefs and self-esteem.

- In providing effective feedback, it should close the gap between current and desired performance.

- The information provided by feedback should provide information to help shape teachers' teaching.

In Bennett's view (2011), essentially, formative assessment should suggest how instruction should be modified, while, at the same time, impressionistically suggesting to the teacher what students know and can do. Looking at summative and formative assessment as two sides of the same coin, Bennett (2011) therefore states that summative assessment should, besides fulfilling its primary purposes, advance learning, while formative assessment should add to the teacher's overall informal judgement of student achievement. In this definition, formative assessment does not fall into the category of either test or process, but is rather viewed as a thoughtful integration of process and purposefully designed methods or instruments.

While the work of Stiggins and Chappuis (2005) and Bennett (2011) specifically refer to school classroom practice, we are of the view that these characteristics and principles are equally important and applicable to the teacher education landscape in efforts to develop thoughtful assessment practice among teachers once they start teaching.

\section{EPISTEMOLOGICAL AND ONTOLOGICAL ASSUMPTIONS: CONSTRUCTIVIST UNDERPINNINGS IN STUDENT-CENTRED ASSESSMENTS}

Mention of the work of Black and Wiliam (1998) can be found in any literature on the aspects of assessment and its formative purposes makes. Their work specifically their emphasis on formative assessment as the interaction between teachers, students and subjects within 'communities of practice' - provides a theoretical framework (Higgins, Hartley \& Skelton, 2002). In essence, Black and Wiliam take a constructivist approach to learning, viewing students as more than mere receptacles for transmitted information but rather as active creators and mediators of meaning within their particular learning contexts. The student is therefore not considered as a controlled respondent to stimuli as in the behaviourist paradigm (Karagiorgi \& Symeou, 2005). Gipps (1999) writes that a postmodern world based on constructivist ideas is characterised by the notion that knowledge does not exist objectively or independent of the knower. Ideas around 'truth' and 'knowledge' are not only hugely complex and subjective but also 
politically saturated. Similarly, Lunenberg (2011) explains that constructivism describes the dynamic relationship between how teachers teach and how students learn. In the constructivist view, students are responsible for their own learning, given that there is a learning atmosphere in which teachers value student thinking, where cooperative learning and authentic assessment of student understanding take place. Lunenberg (2011) refers, in this regard, to five principles of constructivist teaching, namely posing problems and their relevance to students, structuring teaching around primary concepts, seeking and valuing students' points of view, adapting curricula to address students' suppositions, and assessing student learning in the context of teaching.

In their discussion of constructivism, Carlile and Jordan (2005) state that the teacher cannot be in charge of the students' learning, since students have to find their own meaning in situations which are inevitably individual because of different experiences of being in the world. Carlile and Jordan (2005) thereby also stress the centrality of student-centred learning and the fostering of independent learning through the use of what they refer to as negotiated learning strategies and learning contracts. These views hold certain implications for practice, namely:

- A teaching approach from the students' perspective and values;

- Acknowledgment of student diversity in terms of ability, age, gender, culture, nationality;

- Encouraging reflection as part of learning;

- Presenting an overview of the topics to be taught, including their purpose and objectives;

- Explanations of the relevance of topics;

- Building on what is already known;

- Encouraging active, discovery and independent learning;

- Giving timely feedback on performance, and

- Constructively aligning objectives, strategies and assessment.

Karagiorgi and Symeou (2005) mirror these views and warn that learning that focuses exclusively on individual construction of knowledge is inadequate. Rather, the students' experiential world is used to negotiate between individual and societal knowledge. These two cannot be separated and form a dialectical relationship. To support this idea that constructivism is not merely based on students' own views but rather a negotiation between individual and societal knowledge, Alters and Nelson (2002) refer to problems with preconceived ideas when it comes to teaching evolution to students in higher education, a topic that is often misunderstood and poorly taught as well as understood. Alters and Nelson (2002) refer to these misconceptions as being either 'from-experience' misconceptions, self-constructed misconceptions, and taught-and-learned misconceptions. Use of constructivist principles could improve in the way in which contentious topics (such as evolution) can be taught if the teacher (or facilitator) is able to provide students with situations in which they can examine the adequacy of, argue about, and test their prior conceptions. Stumbling upon contradictions could allow students a further opportunity to acquire more scientifically 
appropriate concepts, thus becoming increasingly skilled in the process of concept acquisition.

Because of constructivist views that place the student and their experience at the centre of learning, assessment can also not be regarded as objective and purely scientific. Assessment, too, is value laden and socially constructed and is required to be diverse, examining the quality and structure of student learning that has taken place in greater depth (Gipps, 1999). While, for example, it is sufficient to use multiple-choice questions or short-answer tests to test knowledge, other types of assessment (including essays, small group tasks, and projects) are needed to assess the process of learning and understanding to inspire a deeper level of learning (Gipps, 1999). According to Zane (2009), assessment that is founded on constructivist ideas bases learning upon the complex and integrated nature of the real world. Therefore, boundaries in the real world should be reduced to a manageable size, meaning that assessment should be designed to gather evidence across all facets of competency, integrated into the curriculum, sequenced to support a coherent pedagogy of learning, situated in multiple contexts, and should use multiple modes to account for differences across students, domains and contexts.

\section{IMPLICATIONS}

This chapter provided an overview of assessment in teacher education by focusing on student-centred principles of assessment, by virtue of formative assessment and appropriated by constructivist paradigmatic assumptions in a teacher education setting. An illustrative case study was presented as an example to complement the literature on the changing nature of the higher education landscape vis-à-vis student diversity and student numbers at institutions of higher education worldwide. This example concluded with an illustration of one of the ways in which student-centred learning and assessment, using a constructivist approach, plays out in a varied, developmental setting where students add a range of experiences, challenges and reasons for being trained as a professional teachers to the learning opportunity.

In light of the changing face of higher education worldwide, it is important for learning and teaching to take place, to ensure that students are adequately prepared for employment. In ensuring that higher education institutions place learning at the forefront, it has to be ensured that deep approaches to learning are facilitated and developed. One such aspect of the deep approach presents itself in the form of student-centred learning, which implies active engagement in learning and learner responsibility for the management of learning.

Attempts at student-centred learning cannot be effective or plausible in an assessment environment that does not support or echo active engagement as 
espoused by student-centredness. Harlen and James (1997) state that it is important not only that summative and formative assessment be disentangled but also that formative assessment be used in a genuinely formative way. Formative assessment implies practices about what the students know and can do (Bennett, 2011). In this regard, Gipps' (1999) words are noteworthy and echo the sentiments of this chapter:

Perhaps most important, we need to encourage teachers to bring pupils in to the process of assessment, in order to recognize their social and cultural background, and into selfassessment, in order to develop their evaluative and metacognitive skills. All of these acts are, on the basis of this review, both possible and necessary if assessment is to be more equitable and fulfil its promise to aid and support high quality learning. (p. 387)

\section{REFERENCES}

Ahmed, N., \& and Teviotdale, W. (2008). Formative assessment in higher education. In BMAF Annual Conference 2008. The Learning and Teaching Agenda in the UK: National Perspectives but Common Concerns? 28-30 April. Edinburgh, UK. (Unpublished).

Alters, B. J., \& Nelson, C. E. (2002). Perspective: teaching evolution in higher education. Evolution, 56(10), 1891-1901.

Baeten, M., Kyndt, E., Struyven, K., \& Dochy, F. (2010). Using student-centred learning environments to stimulate deep approaches to learning: Factors encouraging or discouraging their effectiveness. Education Research Review, 5(3), 243-260.

Barrington, E. (2004). Teaching to student diversity in higher education: How Multiple Intelligence Theory can help. Teaching in Higher Education, 9(4), 421-434.

Bennett, R. E. (2011). Formative assessment: a critical review. Assessment in Education, 18(1), 5-25.

Black, P. (1998). Testing: Friend or foe? Theory and practice of assessment and testing. New York: RoutledgeFalmer.

Black, P., \& Wiliam, D. (1998). Assessment and classroom learning. Assessment in Education, 5(1), 7-74.

Boston, C. (2002). The concept of formative assessment. Practical Assessment, Research \& Evaluation, 8(9).

Boud, D., \& Falchikov, N. (2007). Aligning assessment with long-term learning. Assessment and Evaluation in Higher Education, 31(4), 399-413.

Brookhart, S. M. (2001). Successful students' formative and summative uses of assessment information. Assessment in Education, 8(2), 153-168.

Carless, D. (2015). Learning-oriented assessment: Conceptual bases and practical implications. Innovations in Education and Teaching International, 44(1), 57-66.

Carlile, O., \& Jordan, A. (2005). It works in practice, but will it work in theory? The theoretical underpinnings of pedagogy. In G. O'Neill, S. Moore, \& B. McMullin (Eds.), Emerging issues in the practice of university learning and teaching (pp. 11-25). Dublin: AISHE.

Earl, L. M. (2013). Assessment as learning: Using classroom assessment to maximise learning. Thousand Oaks, CA: Corwin Press.

Gareis, R., \& Grant, L. W. (2015). Teacher-made assessments: How to connect curriculum, instruction and student learning. New York: Routledge.

Gipps, C. (1999). Socio-cultural aspects of assessment. Review of Research in Education, 24(1), 355392.

Harlen, W., \& James, M. (1997). Assessment and learning: differences in relationships between formative and summative assessment. Assessment in Education: Principles, Policy \& Practice, 4(3), 365-379. 
Healey, M. (2000). Developing the scholarship of teaching in higher education: A discipline-based approach. Higher Education Research \& Development, 19(2), 169-189.

Higgins, R., Hartley, P., \& Skelton, A. (2002). The conscientious consumer: reconsidering the role of assessment feedback in student learning. Studies in Higher Education, 27(1), 53-64.

Kanjee, A., \& Mthembu, J. (2015). Assessment literacy of foundation phase teachers: An exploratory study. South African Journal of Childhood Education, 5(1), 142-168.

Karagiorgi, Y., \& Symeou, L. (2005). Translating constructivism into instructional design: potential and limitations. Journal of Educational Technology \& Society, 8(1), 17-27.

Lea, S. J., Stephenson, D., \& Troy, J. (2003). Higher education students' attitudes to student-centred learning: beyond 'educational bulimia'? Studies in Higher Education, 28(3), 321-334.

Lunenberg, F.C. (2011). Critical Thinking and Constructivism Techniques for Improving Student Achievement. National forum of teacher education journal volume 21, (3), 1-9.

Ma, J., \& Zhou, D. (2000). Fuzzy set approach to the assessment of student-centered learning. IEEE Transactions on Education, 43(2), 237-241.

McMillan, J. H. (Ed.). (2007). Formative classroom assessment: Theory into practice. New York: Teachers College Press.

Nicol, D. J., \& Macfarlane-Dick, D. (2006). Formative assessment and self-regulated learning: a model and seven principles of good feedback practice. Studies in Higher Education, 31(2), 199-218.

Postareff, L., Lindblom-Ylänne, S., \& Nevgi, A. (2007). The effect of pedagogical training on teaching in higher education. Teaching and Teacher Education, 23(5), 557-571.

Rust, C. (2002). The impact of assessment on student learning. Active Learning in Higher Education, 3(2), 145-158.

Scriven, M. (1967). The methodology of evaluation. In: R. W. Tyler, R. M. Gagne, \& M. Scriven (Eds.), Perspectives of curriculum evaluation (pp. 90-102). Chicago, IL: Rand McNally.

Stiggins, R., \& Chappuis, J. (2005). Using student-involved classroom assessment to close achievement gaps. Theory Into Practice, 44(1), 11-18.

Thorndike, E. L. (1931). Human learning. The Century psychology series. New York \& London: The Century Co.

Yorke, M. (2003). Formative assessment in higher education: Moves towards theory and the enhancement of pedagogic practice. Higher Education, 45(4), 477-501.

Zane, T. W. (2009). Performance assessment design principles gleaned from constructivist learning theory (Part 1). TechTrends, 53(1), 81-89. 